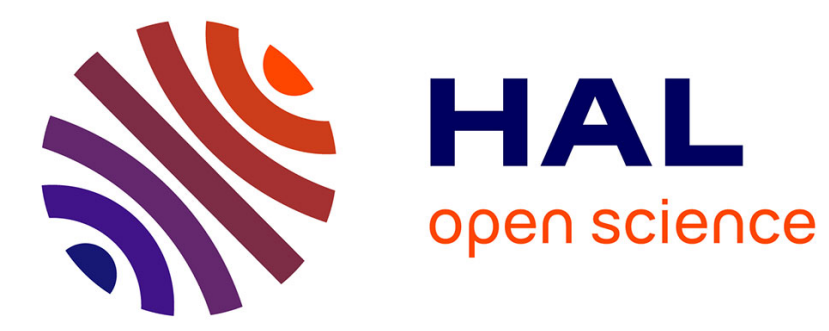

\title{
Well-Defined $\beta$-Diketiminatocobalt(II) Complexes for Alkene Cyclohydroamination of Primary Amines
}

Clément Lepori, Pablo Gómez-Orellana, Allissa Ouharzoune, Régis Guillot, Agusti Lledós, Gregori Ujaque, Jérôme Hannedouche

\section{To cite this version:}

Clément Lepori, Pablo Gómez-Orellana, Allissa Ouharzoune, Régis Guillot, Agusti Lledós, et al.. WellDefined $\beta$-Diketiminatocobalt(II) Complexes for Alkene Cyclohydroamination of Primary Amines. ACS Catalysis, 2018, 8 (5), pp.4446-4451. 10.1021/acscatal.8b00631 . hal-02391919

\section{HAL Id: hal-02391919 https://hal.science/hal-02391919}

Submitted on 26 Aug 2021

HAL is a multi-disciplinary open access archive for the deposit and dissemination of scientific research documents, whether they are published or not. The documents may come from teaching and research institutions in France or abroad, or from public or private research centers.
L'archive ouverte pluridisciplinaire HAL, est destinée au dépôt et à la diffusion de documents scientifiques de niveau recherche, publiés ou non, émanant des établissements d'enseignement et de recherche français ou étrangers, des laboratoires publics ou privés. 


\title{
Well-Defined $\beta$-Diketiminatocobalt(II) Complexes For Alkene Cyclohydroamination of Primary Amines
}

\author{
Clément Lepori, $\uparrow$ Pablo Gómez-Orellana, $\ddagger$ Allissa Ouharzoune, $\uparrow$ Régis Guillot, $\uparrow \perp$ Agusti Lledós, ${ }^{*} \dagger$ \\ Gregori Ujaque, $*+$ and Jérôme Hannedouche* ${ }^{+} \perp$ \\ $\dagger$ Institut de Chimie Moléculaire et des Matériaux d'Orsay, UMR 8182, Université Paris-Sud, Rue du doyen Georges Poitou, \\ Orsay, F-91405, France, $\ddagger$ Departament de Química, Universitat Autònoma de Barcelona, 08193 Cerdanyola del Valles, \\ Catalonia, Spain, $\perp$ CNRS, Orsay, F-91405, France.
}

\section{Supporting Information Placeholder}

Over the years, the catalytic alkene hydroamination - the direct addition of an amine across a carbon-carbon double bond - has received considerable interest among the scientific community as an appealing route to valuable nitrogen-containing compounds from ubiquitous amines and olefins. ${ }^{1}$ The general concern for sustainable metal catalysis has recently stimulated the exploration of earth-abundant, first-row late transition metals for the development of eco-compatible hydroamination catalysts with a wide applicability. ${ }^{1 \mathrm{c}}$ Although still in its infancy, this exploration has already led to outstanding advances with $\mathrm{Zn}^{2}{ }^{2} \mathrm{Cu}^{3}$ or $\mathrm{Fe}^{4}$ metal relying on either a classical ${ }^{2,3 a-b, 4 a-b}$ or a formal hydroamination approach such as metal-hydride mediated umpolung electrophilic amination ${ }^{3 c, 4 c}$ or hydrogen atom ${ }^{4 d}$ transfer. However, although these reports by formal hydroamination have advanced the state of the art, they are far from the concept of atom and step economy of the original hydroamination reaction, and so progress in the direction of "truly" hydroamination systems from earth abundant transition metal is still in high demand. In this context, there is, to our knowledge, no report on the cobaltcatalyzed hydroamination of unactivated alkenes. Only a single but interesting report by Shigehisa et al. has disclosed a Cocatalyzed intramolecular $\mathrm{C}-\mathrm{N}$ bond formation by a closely related formal hydroamidation reaction of protected amines bearing electron-withdrawing groups (EWG) and requiring a substoichiometric amount of oxidizing electrophilic fluorine agent and reducing silane agent (Scheme 1 (a)). ${ }^{5}$ Herein, we report the first example of cobalt-catalyzed alkene hydroamination of unprotected primary amines under co-reagent-free conditions using well-defined low-coordinate $\beta$-diketiminatocobalt(II) complexes (Scheme 1 (b)).

Scheme 1. (a) Seminal Work on Related Co-catalysed N-H Addition on Unactivated Alkenes; (b) This Work

(a) Previous work - formal hydroamidation by reductive-oxidative cycle

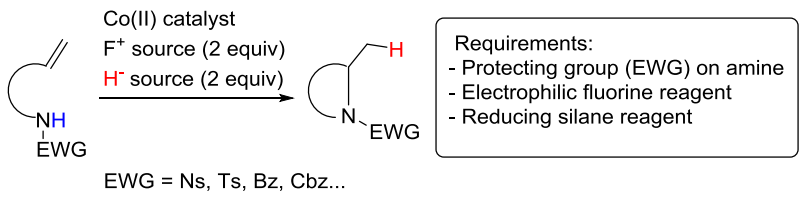

(b) This work - first Co-catalyzed hydroamination

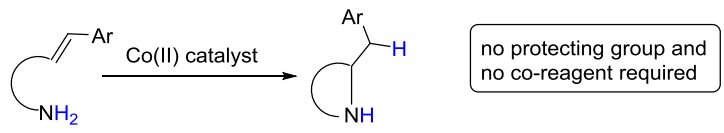

Some of us have recently reported that structurally defined $\beta$ diketiminatoiron(II)-alkyl or -amido complexes, such as $\mathbf{1 a - F e}$ (Scheme 2), have the ability to catalytically promote the highly selective cyclohydroamination of primary aliphatic alkenylamines at mild temperatures, as the first example of iron-catalyzed hydroamination of such electronically unbiased amines. ${ }^{4 a}$ With our concern in base metal catalysis, we have explored the reactivity of analogue complexes derived from cobalt in alkene hydroamination.

Scheme 2. Structures of $\beta$-diketiminatometal(II) complexes $\sum{ }_{-N_{A r}^{N}}^{\mathrm{Ar}} \mathrm{M}-\mathrm{CH}_{2} \mathrm{SiMe}_{3} \cdot \mathrm{THF}$

$\mathrm{Ar}=2,4,6-(\mathrm{Me})_{3} \mathrm{C}_{6} \mathrm{H}_{2}$

1a-Fe $(M=F e) ; 1 a-C o(M=C o)$

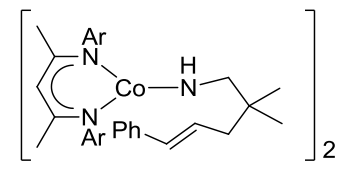

$[1 \mathrm{~b}-\mathrm{Co}]_{2}$
Firstly, the $\beta$-diketiminatocobalt(II) alkyl complex 1a-Co (Scheme 2) was prepared from 2,4-bis $(2,4,6-$ trimethylphenylimido)pentane, $\mathrm{CoCl}_{2}$ and $\mathrm{LiCH}_{2} \mathrm{SiMe}_{3}$ by a twostep metathesis route (via the formation of chloro ate complex S1). ${ }^{6}$ Complex 1a-Co was isolated as a dark-brown air-sensitive crystalline solid that can be stored for weeks at rt without noticeable decomposition. Solid-state analysis of a single crystal reveals that the four-coordinate cobalt atom adopts a pseudotetrahedral 
geometry with a smaller trigonal pyramidal distortion than that found in 1a-Fe $\left(\tau_{\mathrm{Co}}=0.31 \text { vs } \tau_{\mathrm{Fe}}=0.55\right)^{6}($ Figure 1$\left.)\right)^{7,8}$
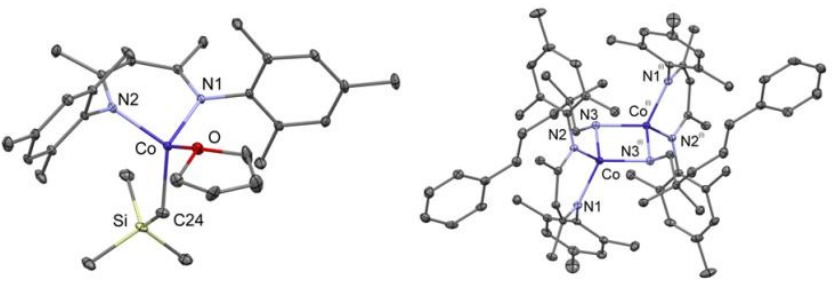

Figure 1. ORTEP drawing of 1a-Co (left) and $[\mathbf{1 b}-\mathbf{C o}]_{2}$ (right). Thermal ellipsoids are shown at the $30 \%$ level. $\mathrm{H}$ atoms have been omitted for clarity.

Our initial evaluation of the catalytic efficiency of 1a-Co focused on the reaction of $\mathbf{2 a}$ as a benchmark reaction under our previously optimized conditions for the iron-catalyzed hydroamination. ${ }^{4 a}$ To our surprise, heating $\mathbf{2 a}$ in toluene at $90{ }^{\circ} \mathrm{C}$ in the presence of $10 \mathrm{~mol} \%$ of $\mathbf{1 a - C o}$ leads to the formation of 3a, 4a, 5a and $\mathbf{6 a}$ in a 4:9:18:61 ratio respectively after $92 \%$ conversion (Table 1, entry 1). This result is in strong contrast with 1a-Fe which delivers under identical conditions the hydroamination product $3 \mathbf{a}$ in $80 \%$ yield with no trace of olefin isomerization product $6 \mathbf{a}^{4 \mathrm{a}}$ To our delight, introducing a phenyl ring at the terminal position of the $\mathrm{C}=\mathrm{C}$ bond of the substrate prevents the alkene isomerization to occur.

Table 1. Screening of Substrates and Conditions of the Cyclohydroamination reaction ${ }^{a}$

\begin{tabular}{|c|c|c|c|c|c|c|}
\hline 2 & 3 & & 4 & 5 & & \\
\hline entry & substrate & $\underset{(\%)^{b}}{2}$ & $\stackrel{3}{(\%)^{b}}$ & $\begin{array}{c}4 \\
(\%)^{b}\end{array}$ & $\begin{array}{c}5 \\
(\%)^{b}\end{array}$ & $\begin{array}{c}\mathbf{6} \\
(\%)^{b}\end{array}$ \\
\hline $1^{c}$ & $\underbrace{\mathrm{NH}_{2}}_{2 a}$ & 8 & 4 & 9 & 18 & 61 \\
\hline $2^{d}$ & & 5 & 93 & 2 & 0 & 0 \\
\hline $3^{e}$ & $2 b$ & 25 & 72 & 2 & 0 & 0 \\
\hline $4^{f}$ & {$[\mathbf{1 b}-\mathbf{C o}]_{2}$} & 8 & 90 & 1 & 1 & 0 \\
\hline $5^{g}$ & {$[\mathbf{1 b}-\mathbf{C o}]_{2}$} & 56 & 0 & 44 & 0 & 0 \\
\hline $6^{g, h}$ & {$[\mathbf{1 b}-\mathbf{C o}]_{2}$} & 58 & 25 & 17 & 0 & 0 \\
\hline
\end{tabular}

${ }^{a}$ Reaction conditions: $[2]=0.96 \mathrm{M}, 10 \mathrm{~mol} \%$ 1a-Co, toluene, $90{ }^{\circ} \mathrm{C}, 24 \mathrm{~h}$ unless otherwise stated. ${ }^{b}$ Determined by GC analysis. ${ }^{c} 3$ h. ${ }^{d}[\mathbf{2 b}]=0.81 \mathrm{M} .{ }^{e}[\mathbf{2 b}]=0.73 \mathrm{M}, \mathrm{rt}, 47 \mathrm{~h} .{ }^{f} 5.55 \mathrm{~mol} \%[\mathbf{1 b}-$ Co $]_{2}$ as catalyst. ${ }^{g}\left[[\mathbf{1 b}-\mathbf{C o}]_{2}\right]=2.6 \mathrm{mM}$, toluene, $90{ }^{\circ} \mathrm{C}, 24 \mathrm{~h}$. ${ }^{\mathrm{h}}$ With cyclopentylamine ( 1 equiv per $\mathrm{Co}$ ).

Indeed, the hydroamination of $\mathbf{2 b}$ catalyzed by $10 \mathrm{~mol} \%$ of 1a-Co provides $\mathbf{3 b}$ in $93 \%$ yield as almost the sole product without any sign of substrate isomerization (Table 1, entry 2). The reaction can also be run at rt with similar selectivity despite a lower efficiency (Table 1, entry 3). By this methodology, various five- and six-membered nitrogen-heterocycles featuring a phenyl ring attached to the terminal alkene which is either unsubstituted (3b-d, 3j) or substituted by an halogen atom (3f-h), an alkyl (3e) or a methoxy (3i) group were isolated in convenient yields from the corresponding aminoalkenes (Table 2). The exo-cyclization also occurs efficiently from primary amines bearing a dimethylsubstituted allene (2k) or an alkyne (2l-m) functionality.
Nevertheless, up to know, the reaction does not proceed with aminoalkenes unbiased towards cyclization or having a trisubstituted olefin. ${ }^{6}$

Table 2. Reaction Scope ${ }^{a}$
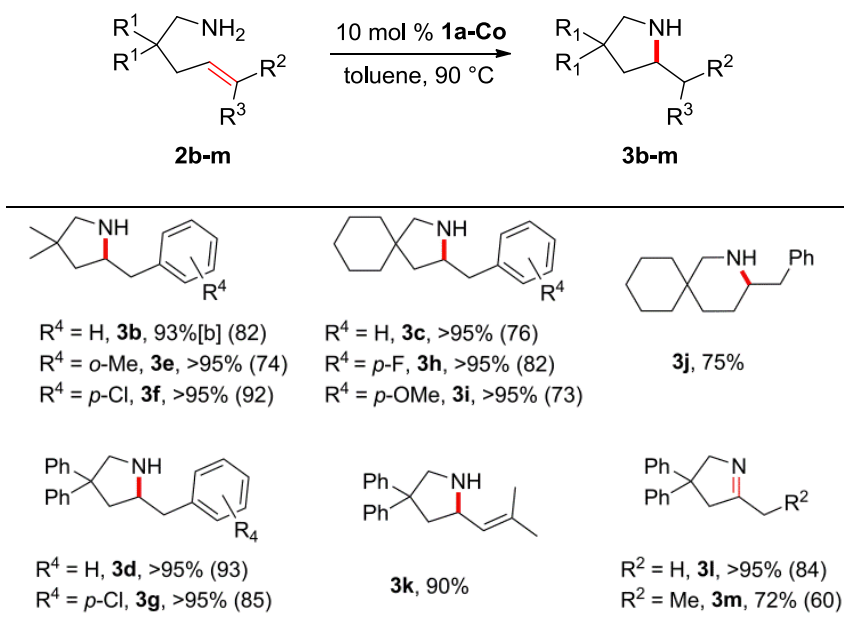

${ }^{a}$ Reaction conditions: [2] $=0.81 \mathrm{M}, 10 \mathrm{~mol} \%$ 1a-Co, toluene, $90{ }^{\circ} \mathrm{C}, 24 \mathrm{~h}$. RMN yield determined using an internal standard unless otherwise stated and isolated yield in brackets. ${ }^{b}$ Determined by GC analysis.

To investigate the reaction mechanism, kinetic analysis of the cyclohydroamination of $\mathbf{2} \mathbf{b}$ was performed by monitoring the concentration of substrate $\mathbf{2} \mathbf{b}$ over the course of the reaction. Plots of $\ln [\mathbf{2 b}]$ vs time are linear to at least 3 half-lives over a $0.51-1.41$ $\mathrm{M}$ initial concentration range and are consistent with first-order kinetics in [2b]. A linear relationship between $k_{\mathrm{obs}}$ and [1a-Co] over a fourfold concentration range $([\mathbf{1 a}-\mathbf{C o}]=0.041-0.161 \mathrm{M})$ indicates a first order dependence in catalyst concentration and provides the empirical rate law displayed in eq 1 with $k_{\mathrm{H}}(363 \mathrm{~K})=$ $6.6 \times 10^{-4} \mathrm{M}^{-1} \mathrm{~s}^{-1}$

$$
-\frac{\mathrm{d}[\mathbf{2} \mathbf{b}]}{\mathrm{dt}}=k_{H}\left[\mathbf{1} \mathbf{a} \_\mathbf{C o}\right]^{1}[\mathbf{2} \mathbf{b}]^{1}
$$

This second-order rate law may reflect mono-association of the substrate with a monomeric cobalt species prior to the ratelimiting step and is consistent with several reported mechanisms such as a proton-assisted concerted C-N/C-H bond-forming mechanism $^{9 \mathrm{a}-\mathrm{d}}$ or a stepwise insertive mechanism ${ }^{9 \mathrm{e}, 4 \mathrm{a}}$ with a turnover-limiting aminolysis event. Further measurement of the rate of cyclization of $N$-deutero-amine $\left[\mathrm{D}_{2}\right]-\mathbf{2 b}$ with $\mathbf{1 a - C o}$ gives $k_{\mathrm{D}}$ $(363 \mathrm{~K})=6.8 \times 10^{-4} \mathrm{M}^{-1} \mathrm{~s}^{-1}$ and leads to no observation of primary kinetic isotope effect $(\mathrm{KIE})\left(\mathrm{k}_{\mathrm{H}} / \mathrm{k}_{\mathrm{D}}=0.97\left(90^{\circ} \mathrm{C}\right)\right)$. Eyring analysis for the cyclization of $\mathbf{2 b}$ over a $353-383 \mathrm{~K}$ temperature range afford the following activation parameters: $\Delta \mathrm{H}^{\neq}=+15.9 \mathrm{kcal} \mathrm{mol}^{-}$ ${ }^{1}, \Delta \mathrm{S}^{\ddagger}=-29.7 \mathrm{cal} \mathrm{mol}^{-1} \mathrm{~K}^{-1}$.

To gain a better insight into the nature of the cyclization step, we endeavor to isolate the initial catalyst-substrate intermediate and study its reactivity. The stoichiometric reaction of 1a-Co and $\mathbf{2 b}$ at $\mathrm{rt}$ leads to the isolation of cobalt amido complex $[\mathbf{1 b}-\mathbf{C o}]_{2}$ as a dark green solid in $89 \%$ (Scheme 2). X-ray diffraction analysis confirms the solid-state structure of $[\mathbf{1 b}-\mathbf{C o}]_{2}$ as a centrosymmetric amido-bridged dimer (Figure 1). The stoichiometric reactivity of isolated $[\mathbf{1 b}-\mathbf{C o}]_{2}$ was then tested by heating a toluene slurry of the dimer for $24 \mathrm{~h}$ at $90{ }^{\circ} \mathrm{C}$. GC analysis reveals the formation of $\mathbf{4 b}$ in $44 \%$ yield as the sole insertion product, concomitantly with unreacted $\mathbf{2 b}$ in $56 \%$ yield (Table 1 , entry 5 ). It is worth noting that $[\mathbf{1 b}-\mathbf{C o}]_{2}$ is also capable of catalytically mediating the hydroamination of $\mathbf{2} \mathbf{b}$ with similar efficiency as its 
alkyl precursor (Table 1, entries 4 vs 2). As C-N bond formation clearly occurs directly from $[\mathbf{1 b}-\mathbf{C o}]_{2}$ in the absence of additional proton source, this stoichiometric experiment militates against a proton-assisted concerted mechanism. The stereochemistry of the cyclization was further elucidated by ${ }^{1} \mathrm{H}$ NMR ${ }^{3} J_{\mathrm{H}, \mathrm{H}}$ coupling constant measurements of the tosylated products arising from cyclization of $N$-deutero-amines $\left[\mathrm{D}_{2}\right]-(E)-\mathbf{3 d}$ and $\left[\mathrm{D}_{2}\right]-(Z)-\mathbf{3 d}$ These experiments provide exclusively products with deuterium located at the $\beta$-position of the nitrogen atom and with a formal syn-addition of the N-D bond across the $\mathrm{C}=\mathrm{C}$ bond. ${ }^{6}$

The reaction mechanism for $\mathbf{2 b}$ was also investigated by means of DFT calculations. ${ }^{10}$ Among the mechanisms evaluated, the one with the most feasible Gibbs energy profile is shown in Figure 2. ${ }^{11}$ The relative stability of doublet and quartet spin states were systematically evaluated obtaining the later as the most stable one. ${ }^{6}$ The mechanism can be divided in two parts, one for generating the active species, III_A3, and another for the catalytic cycle itself. The generation of the active species, III_A3 takes place by a proton transfer from the coordinated reactant to the $\mathrm{CH}_{2} \mathrm{SiMe}_{3}$ ligand, I_A1 (Figure 2 and Scheme 3). This step produces intermediate II_A1, with a Gibbs energy barrier of 29.2 kcal mol ${ }^{-1}$, generating an amido group ligand and $\mathrm{SiMe}_{4}{ }^{12}$ The formed $\mathrm{SiMe}_{4}$ of II_A1 is then replaced by a second aminoalkene reactant molecule producing active species III_A3 at $-11.4 \mathrm{kcal}$ $\mathrm{mol}^{-1}$. In turn, intermediate II_A1 can also form $[\mathbf{1 b}-\mathbf{C o}]_{2}$ that probably corresponds to the resting state of the catalyst once the reactant is consumed (Figure 2 and Scheme 3 ). ${ }^{13}$ Its optimized structure resembles that of X-ray analysis. This species can catalyze the reaction by forming back the monomeric species (Table 1 , entry 4).

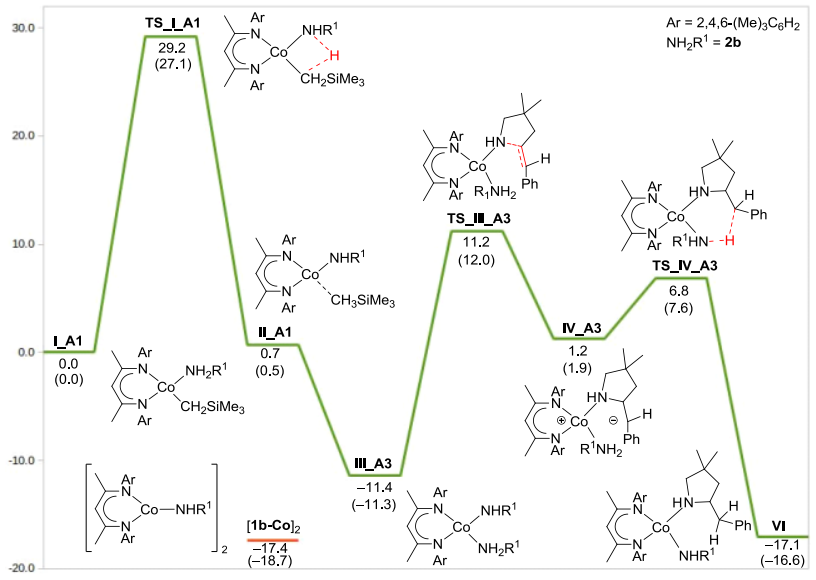

Figure 2. Calculated Gibbs energy profile $(\mathrm{T}=298 \mathrm{~K}$ (in brackets $\mathrm{T}=363 \mathrm{~K}$ ); energies in $\mathrm{kcal} \mathrm{mol}^{-1}$ )

The catalytic cycle contains three steps: (i) intramolecular cyclization by nucleophilic attack of coordinated amido group to the non-coordinated alkene, (ii) proton transfer from a second coordinated aminoalkene to the cyclized amino ligand, and (iii) substitution of the product by a new reactant (Scheme 3). The $\mathrm{C}-\mathrm{N}$ bond formation step, with a relative barrier of $22.6 \mathrm{kcal} \mathrm{mol}^{-1}$, corresponds to the rate determining cyclization step, and is in very good agreement with $\Delta \mathrm{G}^{\neq}=24.6 \mathrm{kcal} \mathrm{mol}^{-1}$ calculated from experimental activation parameters at $\mathrm{T}=298.15 \mathrm{~K}$. The large and negative activation entropy determined experimentally also agrees with a step that involves a cyclization process. Intermediate IV_A3, which lies at $1.2 \mathrm{kcal} \mathrm{mol}^{-1}$, does not have direct interaction between $\mathrm{Co}$ and $\mathrm{C}_{2}$ (distance of $3.649 \AA$ A; Scheme 3 and Figure S11). From this intermediate, there is a proton transfer between the coordinated aminoalkene and the cyclized amino ligand, with an energy barrier of $5.6 \mathrm{kcal} \mathrm{mol}^{-1}$. It generates in- termediate VI, with a relative Gibbs energy of $-17.1 \mathrm{kcal} \mathrm{mol}^{-1}$, that has the hydroamination product coordinated. Replacement of the product by a new aminoalkene molecule closes the catalytic cycle (Scheme 3). This proposed stepwise non-insertive mechanism is the most favorable one among, inter alia, the insertive mechanism. All the attempts to find a concerted non-insertive pathway has conducted to this stepwise mechanism. The absence of KIEs is explained by the fact that the proton transfer step (TS_IV_A3 at $6.8 \mathrm{kcal} \mathrm{mol}^{-1}$ ) is lower in energy than the cyclization step (TS_III_A3 at $11.2 \mathrm{kcal} \mathrm{mol}^{-1}$ ) (Figures 2 and 3).

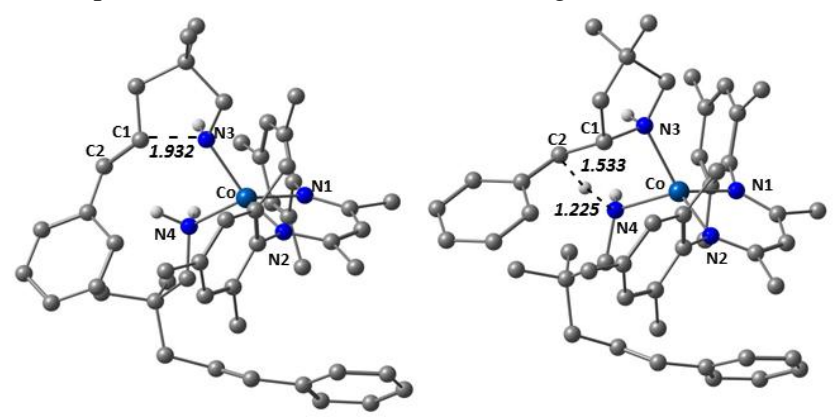

Figure 3. Optimized structures for TS_III_A3 (left) and TS_IV_A3 (right) (distances in $\AA$ ).

The observation of a syn-addition of N-D bond across the $\mathrm{C}=\mathrm{C}$ bond, can be justified by the proposed mechanism if the rotation around $\mathrm{C}_{1}-\mathrm{C}_{2}$ bond (see IV_A3 in Scheme 3) is higher in energy than the proton transfer. Then, proton transfer would be fast enough to avoid rotation around $\mathrm{C}_{1}-\mathrm{C}_{2}$ bond, producing a formal syn-addition of the $\mathrm{N}-\mathrm{H}$ bond across the $\mathrm{C}=\mathrm{C}$ bond. The relative barrier for the proton transfer is $5.6 \mathrm{kcal} \mathrm{mol}^{-1}$, whereas the rotation is estimated to be $14.4 \mathrm{kcal} \mathrm{mol}^{-1}$, thus explaining the experimental observation of a syn-addition. The mechanism is also in agreement with the experimental observation that the reaction of $[\mathbf{1 b}-\mathbf{C o}]_{2}$ in the presence of cyclopentylamine (1 equiv) as an additional proton source generates $\mathbf{3 b}$ (and $\mathbf{4 b}$ ) (Table 1, entry 6).

\section{Scheme 3. Proposed Reaction Mechanism ${ }^{a}$}

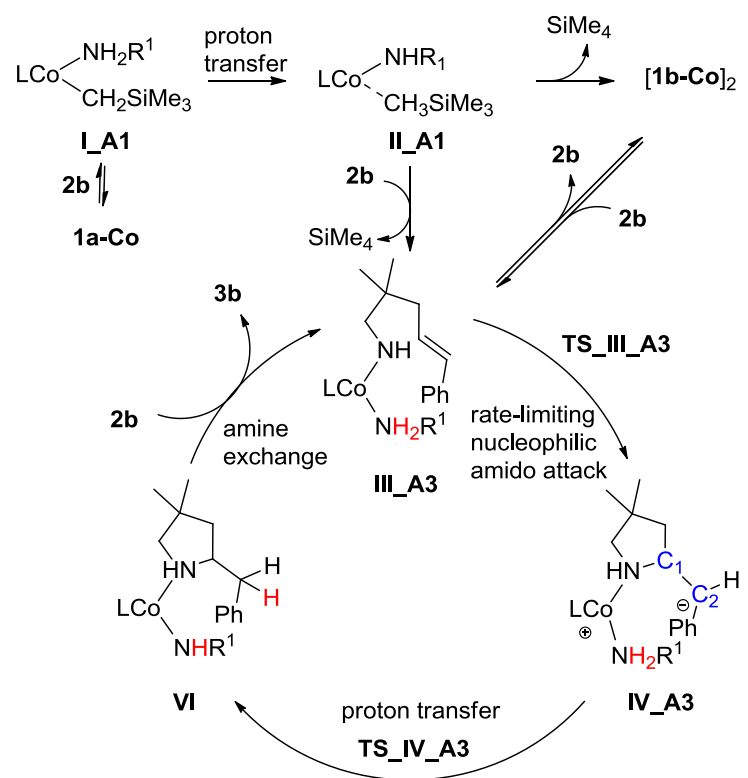

${ }^{a} \mathrm{NH}_{2} \mathrm{R}^{1}=\mathbf{2 b}$, L represents $\beta$-diketiminate ligand.

In conclusion, we have established that novel well-defined $\beta$ diketiminatocobalt(II) alkyl complex 1a-Co is an efficient precatalyst for the hydroamination of unprotected primary amines 
tethered to an aryl alkene under mild and co-reagent free conditions. This is the first example of cobalt-catalyzed alkene hydroamination reaction of unprotected and electronically unbiased primary amines. DFT studies, supported by stoichiometric reactivity experiments, have shown that the reaction operates through a stepwise non-insertive mechanism as original alternative to the classically reported hydroamination mechanisms. This mechanism entails nucleophilic attack of the amido group of monomeric cobalt(II) amidoalkene-aminoalkene adduct intermediate to the non-coordinated pendant alkene as the ratedetermining cyclization step associated subsequently to a rapid proton transfer from the coordinated substrate to the resulting cyclized adduct. This proposed mechanism is in agreement with the empirical second-order rate law, no KIE observation, the synaddition of N-D bond across the $\mathrm{C}=\mathrm{C}$ bond, and the activation parameters determined experimentally. The outcome of this work will help guide the rational design of base metal catalysts with improved reactivity and alternative selectivity patterns. Further studies in this direction are currently ongoing.

\section{ASSOCIATED CONTENT}

\section{Supporting Information}

The Supporting Information is available free of charge on the ACS Publications website.

Experimental procedures, kinetic and isotopic labelling studies, characterization, computational details and copies of NMR spectra (PDF)

Crystallographical data for complex S1 (CIF)

Crystallographical data for complex 1a-Co (CIF)

Crystallographical data for complex $[\mathbf{1 b}-\mathbf{C o}]_{2}(\mathrm{CIF})$

\section{AUTHOR INFORMATION}

\section{Corresponding Author}

*jerome.hannedouche@u-psud.fr

*gregori.ujaque@uab.cat

*agusti@klingon.uab.es

\section{ORCID}

Jérôme Hannedouche: 0000-0001-5278-3906

Gregori Ujaque: 0000-0001-5896-9998

Agusti Lledós: 0000-0001-7909-422X

\section{Notes}

The authors declare no competing financial interests.

\section{ACKNOWLEDGMENT}

Financial supports from MENSR, Univ Paris Sud, CNRS, the Spanish MINECO: CTQ2017-87889-P, Red ORFEO-CINQA (CTQ2016-81797-REDC) and FPI grant to P. Gómez-Orellana, are gratefully acknowledged.

\section{REFERENCES}

(1) (a) Huang, L.; Arndt, M.; Gooßen, K.; Heydt, H.; Gooßen, L. J. Chem. Rev. 2015, 115, 2596-2697. (b) Bernoud, E.; Lepori, C.; Mellah, M.; Schulz, E.; Hannedouche, J. Catal. Sci. Technol. 2015, 5, 2017-2037. (c) Lepori, C.; Hannedouche, J. Synthesis 2017, 49, 1158-1167. (d) Hesp K. D.; Stradiotto, M. ChemCatChem 2010, 2, 1192-1207.

(2) (a) Chilleck, M. A.; Hartenstein, L.; Braun, T.; Roesky, P. W.; Braun B. Chem. Eur. J. 2015, 21, 2594-2602. (b) Mukherjee, A.; Sen, T. K.; Ghorai, P. K.; Samuel, P. P.; Schulzke, C.; Mandal, S. K. Chem. Eur. J. 2012, 18, 10530-10545. (c) Pissarek, J.-W.; Schlesiger, D.; Roesky, P. W.; Blechert, S. Adv. Synth. Catal. 2009, 351, 2081-2085.

(3) (a) Blieck, R.; Bahri, J.; Taillefer, M.; Monnier, F. Org. Lett. 2016 , 18, 1482-1485. (b) Ohmiya, H.; Moriya, T.; Sawamura, M. Org. Lett. 2009, 11, 2145-2147. (c) review on copper hydride-catalyzed formal hydroamination: Pirnot, M. T.; Wang, Y.-M.; Buchwald, S. L. Angew. Chem. Int. Ed. 2016, 55, 48-57.

(4) (a) Bernoud, E.; Oulié, P.; Guillot, R.; Mellah, M.; Hannedouche, J. Angew. Chem. Int. Ed. 2014, 53, 4930-4934. (b) Komeyama, K.; Morimoto, T.; Takaki, K. Angew. Chem. Int. Ed. 2006, 45, 2938-2941. (c) Huehls, C. B.; Lin, A.; Yang, J. Org. Lett. 2014, 16, 3620-3623. (d) Gui, J.; Pan, C.-M.; Jin, Y.; Qin, T.; Lo, J. C.; Lee, B. J.; Spergel, S. H.; Mertzman, M. E.; Pitts, W. J.; La Cruz, T. E.; Schmidt, M. A.; Darvatkar, N.; Natarajan, S.; Baran, P. S. Science 2015, 348, 886-891.

(5) Shigehisa, H.; Koseki, N.; Shimizu, N.; Fujisaw, M.; Niitsu, M.; Hiroya, K. J. Am. Chem. Soc. 2014, 136, 13534-13537.

(6) See Supporting Information for details and/or other explored mechanisms and spin states.

(7) For examples of three-coordinate $\beta$-diketiminatocobalt(II) $\mathrm{sp}^{3}$-alkyl complexes: (a) Young, J. F.; Yap, G. P. A.; Theopold, K. H. J. Chem. Crystallogr. 2009, 39, 846-848. (b) Chen, C.; Dugan, T. R.; Brennessel, W. W.; Weix, D. J.; Holland, P. L. J. Am. Chem. Soc. 2014, 136, 945-955.

(8) DFT optimized structure of 1a-Co is very similar to that obtained by X-ray analysis and assigns a quartet spin state to this compound as noticed by solution magnetic moment measurement. ${ }^{6}$

(9) (a) Manna, K.; Kruse, M. L.; Sadow, A. D. ACS Catal., 2011, 1, 1637-1642. (b) Leitch, D. C.; Platel, R. H.; Schafer, L. L. J. Am. Chem. Soc. 2011, 133, 15453-15463. (c) Dunne, J. F.; Fulton, D. B.; Ellern, A.; Sadow, A. D. J. Am. Chem. Soc. 2010, 132, 17680-17683. (d) Arrowsmith, M.; Crimmin, M. R.; Barrett, A. G. M.; Hill, M. S.; KociakKöhn, G.; Procopiou, P. A. Organometallics 2011, 30, 1493-1506. (e) Tobisch, S. Dalton Trans. 2012, 41, 9182-9191.

(10) Related DFT analysis of hydroamination reactions: (a) CouceRios, A.; Lledós, A.; Ujaque, G. Chem. Eur. J. 2016, 22, 9311-9320. (b) Couce-Rios, A.; Kovács, G.; Ujaque, G.; Lledós, A. ACS Catal. 2015, 5, 815-829. (c) Kovács, G.; Lledós, A.; Ujaque, G. Angew. Chem. Int. Ed. 2011, 50, 11147-11151. (d) Strom, A. E.; Balcells, D.; Hartwig, J. F. ACS Catal. 2016, 6, 5651-5665. (e) Tobisch, S. Chem. Sci. 2017, 8, 4410-4423.

(11) Optimization geometries and Gibbs energies are computed in toluene at M06 level; for Co the SDD pseudopotential along with its associated basis set, adding $\mathrm{f}$ orbitals, and a triple- $\varsigma$ basis set for the rest of atoms was employed. ${ }^{6}$

(12) Monitoring the reaction of $\mathbf{1 a - C o}$ ( 1 equiv) and $\mathbf{2 b}$ ( 2 equiv) at $90^{\circ} \mathrm{C}$ by ${ }^{1} \mathrm{H}$ NMR experiments reveals full disappearance of the methyl signals of $\mathrm{CH}_{2} \mathrm{SiMe}_{3}$ fragment of $\mathbf{1 a - C o}$ in less than 10 minutes. Additionally, no induction period was noticed under catalytic conditions. ${ }^{6}$ tions.

(13) This dimer is also generated under stoichiometric reaction condi- 


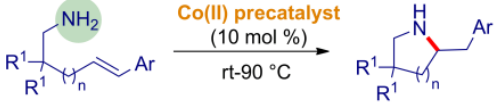

$$
\begin{aligned}
& n=1,2
\end{aligned}
$$

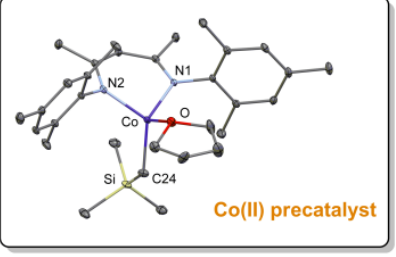

$\checkmark$ Protecting-group free

$\checkmark$ No co-reagent required

$\checkmark$ Mechanism studies 